\title{
A Abordagem do Tema Sexualidade no Contexto Familiar: o Ponto de Vista de Mães de Adolescentes
}

\author{
Sabrina Dal Ongaro Savegnago \\ Universidade Federal do Rio de Janeiro, RJ, Brasil.
}

\author{
Dorian Mônica Arpini \\ Universidade Federal de Santa Maria, RS, Brasil.
}

\begin{abstract}
Resumo: O objetivo deste estudo consiste em apresentar alguns aspectos referentes ao diálogo sobre sexualidade entre pais e adolescentes, a partir do ponto de vista de mulheres que possuem filhos(as) adolescentes. Foram realizadas entrevistas semiestruturadas e grupos focais com mães que frequentavam um Centro de Referência em Assistência Social de uma cidade do interior do Rio Grande do Sul. Os resultados, após análise de conteúdo, indicam que os assuntos relacionados à sexualidade mais abordados pelas mães com os(as) filhos(as) adolescentes foram a prevenção de doenças e gravidez, com destaque para o uso do preservativo. A maioria das participantes referiu ter mais facilidade para conversar com as filhas adolescentes do que com os filhos. As participantes apresentaram tanto a percepção de que os adolescentes já teriam informações suficientes sobre o assunto quanto a ideia de que eles esperam esclarecimentos e abertura para o diálogo por parte dos pais. As considerações finais apontam para a importância de que as conversas sobre sexualidade não se reduzam às questões preventivas, e destacam a necessidade de que ambos os genitores assumam ativamente seus papéis com relação ao diálogo sobre o tema com filhos(as) adolescentes.

Palavras-chave: Adolescente, Família, Sexualidade, Comunicação.
\end{abstract}

\section{Approach to the Theme of Sexuality in the Family Context: The Point of View of Adolescents' Mothers}

\begin{abstract}
The aim of this study is to present some aspects related to the dialogue of sexuality between parents and teenagers, from the point of view of women with teenage children. Semistructured interviews and focal groups were performed with mothers attending a reference center for social assistance in a country town in Rio Grande do Sul State. The results, after the analysis of content, indicated that the sexuality matters most discussed by mothers with their teenage children were: prevention of diseases and pregnancy, and particularly the use of condoms. Most of the participants reported to have more easiness to talk with their teenage daughters than with their sons. Participants reported both that teenagers already have enough information on this subject, and that teenagers expect more clarification and openness to dialogue from their parents. The conclusions point out that dialogues about sexuality do not get reduced to preventive issues, highlighting the need of both, mothers and fathers, actively take on their roles regarding the dialogue on this issue with their teenage children.
\end{abstract}

KeYwords: Teenagers, Family, Sexuality, Communication. 


\title{
El Abordaje del Tema de la Sexualidad en el Contexto Familiar: El Punto de Vista de Madres de Adolescentes
}

\begin{abstract}
Resumen: El objetivo de este trabajo es presentar algunos aspectos relacionados con el diálogo sobre la sexualidad entre padres y adolescentes, desde el punto de vista de mujeres que tienen hijos o hijas en esta edad. Fueron realizadas entrevistas semiestructuradas y grupos focales con madres que participaban de un Centro de Referencia en Asistencia Social de una ciudad del interior del Rio Grande do Sul. Los resultados del Análisis de Contenido indicaron que las cuestiones relacionadas con la sexualidad más abordadas por las madres con hijos adolescentes fueron: la prevención de enfermedades y del embarazo, y, particularmente, el uso de condones. La mayoría de las participantes informó que es más fácil hablar con sus hijas adolescentes que con sus hijos. Las participantes relataron que los adolescentes ya tienen suficiente información sobre el tema, aunque esperan aclaraciones y apertura al diálogo por parte de los padres. Las conclusiones apuntan para la importancia de que las conversaciones sobre la sexualidad no se reduzcan a cuestiones de prevención, y ponen de relieve la necesidad de que ambos, padres y madres, asuman activamente sus funciones en relación al diálogo sobre el tema con sus hijas o hijos adolescentes.

Palabras clave: Adolescente. Familia. Sexualidad. Comunicación.
\end{abstract}

\section{Introdução}

A puberdade, que marca a transformação do corpo infantil em um corpo adulto com possibilidade de reprodução, é reconhecida em todas as culturas. Desde a Grécia antiga até as sociedades indígenas do Brasil, essa transição da infância para a vida adulta é seguida de rituais, os quais desempenham o papel de reinscrever simbolicamente o corpo do púbere, a fim de que passe a assumir um lugar no mundo adulto (Kehl, 2004). Por outro lado, o conceito de adolescência é relativamente recente e teve origem no ocidente. Ainda que determinados componentes psicológicos e corporais tenham sempre existido no jovem, independentemente do momento histórico, a sociedade nem sempre reconheceu as características específicas da adolescência. Assim, em um processo que se iniciou nas nações e culturas industrializadas, os adultos passaram a considerar as demandas e as características fisiológicas e psicológicas próprias da adolescência e começaram a reconhecê-la como uma etapa distinta do desenvolvimento humano. Desse modo, este período passou a ser estudado mais profundamente e configurou-se em um campo de estudo com legitimidade própria (Sprinthall, \& Collins, 2003).

Ao longo da modernidade ocidental, a adolescência foi se tornando uma categoria institucionalizada, compreendida como uma fase natural, universal e inerente ao desenvolvimento humano (Mayorga, 2006). No entanto, destacam-se, por exemplo, sociedades nas quais a adolescência não é reconhecida. Este aspecto fica evidente, por exemplo, em locais onde crianças passam diretamente para o mundo adulto, a partir de casamentos realizados em torno dos 13 anos de idade (Sprinthall, \& Collins, 2003).

Estudos mais recentes da Psicologia Social vêm questionando o paradigma tradicional que pauta a adolescência a partir denoções de universalidadee a-historicidade. Assim, apesar de diversas contribuições da literatura referirem-se à adolescência no seu aspecto geral e universal, as experiências e estudos em torno deste tema têm apontado para uma diversidade de vivências marcando esse período de desenvolvimento. Desse modo, ao se considerar o contexto social, econômico, político e cultural em que o sujeito está inserido, o que implica em uma diversidade, é possível falar em "adolescências". Neste sentido, a definição deste período de desenvolvimento do sujeito não se constitui mais em uma tarefa que implica em estabelecer regras gerais e universais em relação a essa fase, mas em indicar algumas características que podem marcar esse período que se define como uma "etapa entre a infância e vida adulta" (Mayorga, 2006, p. 13).

Uma das questões que, inegavelmente, pode ser indicada como uma parte significativa da vivência dos adolescentes é a questão da sexualidade. Além disso, a 
possibilidade de reprodução vai surgir nesta etapa da organização da sexualidade humana (Freud, 1996/1905; Savietto, \& Cardoso, 2006). Vale salientar que a palavra sexualidade pode ter significados diferentes e referir-se a questões específicas conforme o campo de saber a partir do qual se observa. Sob uma perspectiva biológica, por exemplo, a sexualidade refere-se às funções de diferenciação sexual e de reprodução. Comumente, quando se fala de sexualidade, esta é relacionada aos comportamentos observáveis, à atividade sexual consciente, e suas manifestações funcionais, relacionais e afetivas. Esta concepção é compartilhada pelo discurso do senso comum e pelo discurso médico. No entanto, a partir de Freud, a sexualidade passou a ser compreendida para além desta perspectiva (Desprats-Péquignot, 1992/1994).

Pode-se dizer que a noção de sexualidade passou por transformações ao longo do tempo (Laplanche, \& Pontalis, 1996) e teve como divisor de águas a teoria psicanalítica. A partir do século XX, as concepções de Freud assinalam um entendimento totalmente novo acerca da sexualidade. $\mathrm{O}$ trabalho de Freud expôs pela primeira vez uma visão sistemática da sexualidade a partir do ponto de vista psicanalítico, que se contrapôs às concepções produzidas até então (Desprats-Péquignot, 1992/1994). Salienta-se que a psicanálise atribui grande importância à sexualidade na vida psíquica e no desenvolvimento do ser humano (Laplanche, \& Pontalis, 1996).

De acordo com a teoria psicanalítica ${ }^{1}$, a sexualidade não se refere apenas às atividades sexuais e ao prazer relacionado ao funcionamento do aparelho genital. Trata-se de um conceito muito mais amplo, que designa "toda uma série de excitações e de atividades presentes desde a infância que proporcionam um prazer irredutível à satisfação de uma necessidade fisiológica fundamental (respiração, fome, função de excreção, etc.)" (Laplanche, \& Pontalis, 1996, p. 476). Desse modo, o conceito de sexual é amplo e abrange muitas atividades que não tem relação com os órgãos genitais (Freud, 1996/1940).

Freud não utiliza o termo "adolescência", mas aborda, em especial na obra "Três ensaios sobre a teoria da sexualidade” (1996/1905), pontos fundamentais relacionados à puberdade, "processo que, ainda que ancorado nas transformações corporais, é analisado por Freud enquanto experiência subjetiva de ruptura com a vida infantil e travessia rumo à vida adulta" (Savietto, \& Cardoso, 2006, p. 17). Assim, pode-se inferir que, neste caso, mesmo não utilizando o termo "adolescência", Freud se referia a ela, no sentido de que, ao descrever a puberdade, não se prendia ao seu viés biológico, mas dava ênfase às repercussões psíquicas causadas pela entrada do sujeito nesta etapa da vida (Savietto, \& Cardoso, 2006).

Uma das contribuições significativas de Freud foi a afirmação de que a vida sexual não se inicia na puberdade, mas já se manifesta claramente logo após o nascimento. Assim, na adolescência, etapa fundamental do desenvolvimento psicossexual do sujeito, que é precedida pelo período de latência, ocorre uma retomada do que já havia se iniciado na infância (Freud, (1996/1905). Nessa direção, a adolescência pode ser entendida como um processo psíquico organizador da vida do sujeito, que age de forma retroativa, conferindo sentido à sexualidade infantil, além de dar significado ao que está por vir na fase adulta, tanto no que se diz respeito às escolhas objetais quanto no que se refere à possíveis evoluções patológicas (Marty, \& Cardoso, 2008).

Assim, considerando a importância da questão da sexualidade na adolescência e o fato de que o adolescente pode se deparar com muitas dúvidas, especialmente em relação a essa temática, destaca-se a importância de que encontre na família um espaço onde possa dialogar, ouvir e expor suas dúvidas, opiniões, críticas e ideias, em que estejam presentes compreensão, afeto e respeito (Takiuti, 1997). Brandão (2004) ressalta a importância de que as relações familiares estejam baseadas nos princípios do diálogo, negociação e argumentação, sem deixar de considerar a discussão do tema sexualidade no processo de educação dos filhos. No entanto, pesquisa realizada por Heilborn (2012) verificou que em muitos grupos sociais existe a concepção de que sexualidade não seria assunto para se conversar abertamente entre pais e filhos, pois comprometeria o respeito entre as gerações. Outros estudos também têm apontado o pouco diálogo familiar sobre este tema, a partir da perspectiva de adolescentes (Borges, Latorre, \& Schor, 2007; Borges, Nichiata, \& Schor, 2006; Brandão, 2004; Macedo, Miranda, Pessoa Junior, \& Nobrega, 2013; Savegnago, 2011; Siqueira, Arpini, \& Savegnago, 2011). Pesquisas realizadas com pais e/ou

1. Neste trabalho, as reflexões sobre adolescência e sexualidade têm como base a perspectiva teórica da psicanálise freudiana. Optou-se por esta escolha, principalmente por esta teoria ter trazido importantes contribuições acerca destas temáticas. Em relação a estas questões, sugere-se a consulta às obras "Três ensaios sobre a teoria da sexualidade", "Esboço de psicanálise" e "Os instintos e suas vicissitudes", de Sigmund Freud. 
mães de adolescentes referem dificuldades relatadas por muitos deles para abordar este tema junto aos filhos (Barbosa, Costa, \& Vieira, 2008; Cano, \& Ferriani, 2000; Dias, \& Gomes, 1999; Gubert, Vieira, Pinheiro, Oliveira, \& Costa, 2009; Predebon, 2002; Sousa, Fernandes, \& Barroso, 2006). Este cenário indica que ainda existe um longo caminho a ser trilhado no que se refere à busca por relacionamentos entre pais e filhos baseados no diálogo franco sobre o tema e pela confiança mútua (Borges et al., 2006).

A abertura dos pais para o diálogo sobre sexualidade com os filhos adolescentes pode possibilitar a discussão e a aquisição de orientações que esclareçam dúvidas importantes dos adolescentes, além de apoiá-los no sentido da promoção de vivências saudáveis, seguras e livres de temores em relação à sexualidade (Ressel, Junges, Sehnem, \& Sanfelice, 2011). É fundamental que os pais exponham de forma clara e autêntica seus pontos de vista e princípios, o que por vezes pode ser difícil devido às suas próprias experiências relacionadas à sexualidade. Quando os pais conseguem assumir sua autoridade manifestando seus valores e ideias, estão fornecendo um referencial ao adolescente, a partir do qual ele poderá refletir e fazer suas próprias escolhas de forma segura (Levisky, 1995).

Dialogar sobre sexualidade é algo que deveria ir além da simples transmissão de informações, uma vez que demanda que os pais ultrapassem várias barreiras para alcançarem uma proximidade com as experiências do adolescente e uma sintonia com o momento existencial pelo qual este está passando. Ademais, é um desafio para os pais encontrarem um equilíbrio na transmissão de informações e valores sobre sexo/sexualidade aos filhos, no sentido de que estas não sejam tão restritivas, nem excessivamente permissivas (Dias, \& Gomes, 1999).

A realização deste estudo com mães leva em conta o fato de que, no que se refere ao diálogo sobre sexualidade na família, a mãe é a figura mais referida pelos adolescentes. Estudos já realizados constataram que, quando há algum grau de diálogo sobre sexualidade no âmbito familiar, este se dá majoritariamente com a mãe (Aquino, Almeida, Araújo, \& Menezes, 2006; Borges et al., 2007; Borges, et al., 2006; Bozon, \& Heilborn, 2006; Brandão, 2004; Pick, \& Palos, 1995; Predebon, 2002; Savegnago, 2011). Desse modo, apesar das dificuldades e limitações existentes para se abordar a temática da sexualidade, geralmente são as mães que se esforçam para fazê-lo. Enquanto isso, os pais parecem ter pouca habilidade para o diálogo, muitos são distantes do dia-a-dia dos filhos, ou não são disponíveis para negociações familiares (Brandão, 2004).

Assim, considerando-se todos os aspectos apresentados, o objetivo deste estudo consiste em apresentar alguns aspectos referentes ao diálogo sobre sexualidade entre pais e adolescentes, a partir do ponto de vista de mulheres que possuem filhos adolescentes.

\section{Método}

Com o intuito de alcançar o objetivo proposto e de compreender de forma ampla e profunda a reflexão de mães no que se refere ao diálogo sobre sexualidade com os filhos adolescentes, realizou-se um estudo qualitativo. A pesquisa foi realizada em um Centro de Referência e Assistência Social (CRAS). A escolha do local relaciona-se à identificação de que, dentre os usuários desta instituição, encontravam-se mães de adolescentes oriundas de grupos populares. O CRAS é uma unidade pública estatal descentralizada da política de assistência social, responsável pela organização e oferta de serviços da proteção social básica do Sistema Único de Assistência Social (SUAS) nas áreas de vulnerabilidade e risco social do município. Trata-se de um serviço que propicia o acesso de um grande número de famílias à rede de proteção social de Assistência Social (Brasil, 2005).

Participaram 17 mães de adolescentes, pertencentes a grupos populares de uma cidade do interior do Rio Grande do Sul. Destas, nove foram entrevistadas individualmente (E) e oito participaram de grupos focais. Foram realizados dois grupos focais (GF1 e GF2), com a presença de cinco mães no primeiro e três mães no segundo grupo. A média de idade das participantes foi de 40,94 anos, tendo em média 4,4 filhos. Em relação à escolaridade, a maioria das mães (10), possuía o ensino fundamental incompleto. E em relação à ocupação, oito participantes eram donas de casa, três eram diaristas, duas empregadas domésticas, uma trabalhava com reciclagem de materiais, uma como comerciante, uma como oficineira de artesanato e uma como auxiliar de limpeza. Buscando manter o anonimato das participantes, seus nomes foram substituídos por códigos (por exemplo, M1, M2, M3...) ao longo do texto.

Nas entrevistas, a pesquisadora atuou como guia, visando que cada participante falasse livremente sobre suas ideias e percepções em relação à temática proposta. Os eixos que nortearam as entrevistas foram os seguintes: 1-Abordagem do tema sexualidade na família; 2- Diálogos sobre sexualidade com o filho adolescente; 3 - Assuntos relacionados à sexualidade que são abordados no contexto familiar; 4- Diferenças entre conversar com meninos e 
conversar com meninas sobre este tema; se existem, quais são; 5- Barreiras e dificuldades para que haja esse tipo de conversa com os filhos; Facilitadores para que estes diálogos aconteçam; se existem, quais são e como funcionam; 6- Necessidade/importância de se tratar do tema da sexualidade com os filhos; e 7- O que os adolescentes esperam dos pais em relação às questões envolvendo a sexualidade neste período do desenvolvimento.

Os grupos focais complementaram as entrevistas, visto que nestes, devido à interação de seus membros, foi possível esclarecer temáticas surgidas nas entrevistas individuais. Destaca-se a importância da triangulação das técnicas utilizadas na realização desta pesquisa, uma vez que, ao realizarem-se grupos focais e entrevistas semiestruturadas, foi possível apreender de forma mais profunda a realidade estudada, do que se fosse utilizado apenas um instrumento. O grupo oferece a possibilidade de que as participantes dialoguem entre si; há uma tendência à redução da interferência do pesquisador e o tema pode ser abordado com mais naturalidade, devido à proximidade entre os pares. Assim, entende-se que o uso da técnica de grupo focal foi apropriado, pois, por meio dos grupos, as participantes puderam manifestar-se de forma espontânea, estabelecendo uma discussão sobre a temática, apontando criticamente suas opiniões e tendo uma participação ativa. O objetivo do grupo focal é estimular os participantes para que exponham suas ideias e reajam ao que os outros membros do grupo falam. Dessa forma, as ideias e representações que surgem no grupo são mais influenciadas pela natureza social da interação grupal ao invés de se basearem no ponto de vista de individual, como seria em uma entrevista individual (Gaskell, 2005).

Durante a realização dos grupos focais foi oportunizada a participação espontânea das mães, ficando a pesquisadora no papel de motivadora da discussão e moderadora do grupo. O moderador tem a tarefa de manter ogrupo em interação, com a finalidade de obter informações referentes ao tema da pesquisa. Foram utilizadas como disparadores para a discussão grupal falas de meninas que participaram de uma pesquisa anterior que teve como tema o diálogo sobre sexualidade na família. Destaca-se a importância da utilização destas falas como disparadores, uma vez que as adolescentes do estudo anterior pertenciam ao mesmo contexto socioeconômico das mães participantes desta pesquisa. As vinhetas utilizadas foram as seguintes: 1. "Eles acham que a gente não tá preparada pra sabê daquilo. Mas a gente tá preparada. Tá chegando a idade, a gente tem que sabê disso. A gente tá na idade de sabê essas coisas" (E, 13 anos); 2. "A minha mãe me contava: Se tu beijava tu ia engravidá e daí se tu beijava assim, o homem tinha que comprá uma sementinha e pôr no teu umbigo pra ti ter um nenê, porque senão tu era condenada" (T, 13 anos); 3. "É, tipo quando a gente quer conversar e tipo, 'ah não quero conversá sobre isso', daí... tipo eu, quero conversar sobre sexualidade com a minha mãe, mas a minha mãe nãofala isso comigo" (R, 13 anos); 4. "O máximo que a mãe me falaé: 'Se tu for fazê alguma coisa, tu usa camisinha' (...) A senhora camisinha... [risos]. É, o que eles mais falam... se previní..." (K, 14 anos) (Savegnago, 2011).

Este estudo foi submetido e aprovado, em seus aspectos éticos e metodológicos, pelo Comitê de Ética em Pesquisa com seres humanos da Instituição de Ensino onde os pesquisadores atuam, sob o parecer n ${ }^{\circ} 54850 \mathrm{e}$ o Certificado de Apresentação para Apreciação Ética no 05022712.8.0000.5346. O Termo de Consentimento Livre e Esclarecido foi assinado pelas participantes após terem sido esclarecidos os procedimentos a serem realizados, os objetivos e a justificativa da pesquisa.

As entrevistas e os grupos foram gravados e posteriormente transcritos. As informações foram analisadas por meio do método de Análise de Conteúdo, como proposto por Bardin (1977). Neste artigo, serão apresentados e discutidos os resultados das seguintes categorias: (1) Assuntos mais abordados com os adolescentes em relação à sexualidade; (2) Diferenças em dialogar sobre sexualidade com filhos e filhas adolescentes; e (3) O que os adolescentes esperam dos pais. Estas categorias relacionam-se com os eixos norteadores 3,4 e 7, conforme apresentados anteriormente.

\section{Resultados}

\section{1. "Explicava pra eles que tem que se protegê, que tem que se cuidá": assuntos mais abordados com os adolescentes em relação à sexualidade}

As mães participantes deram ênfase à prevenção de doenças e gravidez, com destaque para o uso da camisinha, como os assuntos relacionados à sexualidade mais tratados com os filhos adolescentes, tanto do sexo masculino quanto do feminino. Esta questão pode ser visualizada nas falas a seguir:

Eu peço pra elas usá camisinha, né. Pro guri também, né (M11, 38 anos, GF1).

O que eu falo mais é sobre a gravidez. (...) E falo muito sobre filho também, muito sobre filho, né. 
Savegnago, Sabrina Dal Ongaro; Arpini, Dorian Mônica (2016). Sexualidade no Contexto Familiar.

Eu explico pra eles, eu mostro pra eles o trabalho que eu passei pra criá eles, né, e que filho não é bem assim... É isso mais que eu falo. E se elas me perguntam sobre uma doença também, eu esclareço, que é bem, né... (M5, 34 anos, E).

Eu acho que isso é o que os pais mais falam, se cuidá, se prevení... (M13, 56 anos, GF1).

Esta preocupação por parte das mães com relação às doenças sexualmente transmissíveis e à gravidez também se fez presente no estudo de Ressel et al. (2011). Tratou-se de uma pesquisa realizada com adolescentes do sexo feminino da cidade de Santa Maria, RS. As participantes relataram a preocupação de seus pais em protegê-las de possíveis riscos relacionados a relações sexuais sem proteção. Outro estudo (Savegnago, \& Arpini, 2014), com adolescentes da mesma cidade, apresentou resultados semelhantes. As meninas participantes destacaram que o assunto referente à sexualidade mais abordado na família era a questão preventiva, com ênfase especial para o uso da camisinha. Pesquisa de Macedo et al. (2013) junto a adolescentes de uma unidade de Educação de Jovens e Adultos (EJA), no município de Jandaíra - RN, apresentou um contexto marcado pela ausência de diálogo familiar sobre sexualidade. Nos raros relatos que indicavam que este diálogo acontecia, este se relacionava especificamente às questões reprodutivas, em especial aos cuidados para evitar-se uma gravidez indesejada.

Em contraponto a isso, um estudo com pais de adolescentes matriculados em uma escola pública de Fortaleza, realizado por Barbosa et al. (2008), constatou que a maioria dos pais relatou não conversar com os filhos sobre medidas preventivas para DST/HIV/AIDS ou sobre a prevenção à gravidez na adolescência. Eles afirmaram não saber falar sobre tais assuntos ou acreditavam que ainda não havia a necessidade de abordar esta temática junto aos adolescentes.

Segundo Ressel et al. (2011), é possível observar nas falas dos pais que ressaltam sobremaneira o uso dos métodos contraceptivos a utilização de uma abordagem familiar da sexualidade limitada ao ato sexual e voltada prioritariamente às questões preventivas. Para estes autores, a argumentação preventiva presente na fala dos pais, especialmente na da mãe, pode representar sinais de uma sexualidade velada, pouco falada e que, quando trazida à tona, é tratada como uma questão perigosa, evidenciando-se seus possíveis riscos e prejuízos.
Cabe ressaltar que, nos dias atuais, além das preocupações gerais dos pais com a questão de como lidar com a adolescência dos filhos, um dos grandes problemas que vem angustiando os adultos que têm filhos adolescentes é a iniciação sexual precoce. Esta questão traz consigo a preocupação com a possibilidade de contágio pelo vírus HIV, pois o número de adolescentes contaminados por este vírus vem crescendo. Esta questão se destaca no conjunto de preocupações dos genitores, pois as influências do contexto social no qual o adolescente está inserido, somadas às características de impulsividade e comportamento desafiador que podem se manifestar neste período, podem resultar no envolvimento do mesmo em comportamentos considerados de risco, como a prática de relações sexuais sem proteção (Pratta, \& Santos, 2007).

A maioria das mães do presente estudo demonstrou estar consciente de que o exercício da sexualidade é uma realidade inegável na vida de seus filhos adolescentes. Desse modo, elas procuram orientá-los desde cedo com relação aos cuidados, pois parece ser esperado que suas vidas sexuais se iniciem bem cedo e esta iniciação parece não sofrer interdição por parte das mães, como demonstra a fala da participante M12 (42 anos, GF1): "A gente sabe que dizê que não é pra fazê não vai adiantá. Aí tem que dizê que eles têm que se previní, né". Nesta afirmação chama atenção, novamente, a ênfase dada à prevenção. De forma semelhante, o estudo de Ressel et al. (2011) mostra que, no discurso dos pais participantes, não havia indicação de proibição ou negação para a vivência da sexualidade, mas houve destaque para a preocupação em relação à prevenção da gravidez.

Ressalta-se a importância da preocupação dos pais com os cuidados a serem tomados pelo adolescente para a prevenção às doenças e à gravidez durante este período. Essa preocupação parece servir como motivação aos pais para a transmissão de importantes informações aos filhos.

Às vez tá uma doença no filho lá e a gente não sabe. Aí eu digo "Qualquer coisa, se tu sentí uma cocerinha ou uma coisa estranha em ti, né, e tu não quisé falá pra mãe, e precisá ir no médico, tu só pede que a mãe te leva. Ou pede dinheiro pra mãe e vai no médico". "Ah mãe, eu sei me cuidá", ele diz assim. Mas a gente, dessa parte ali a gente tá sempre... eu mesma digo "Ah filho, tem dinheiro pra comprá preservativo? Te cuida, meu 
filho". Às vez eu digo "Meu filho, esses preservativo não é só pra evitá doença, é pra evitá criança, evitá filho, evitá doença também..." E aí... isso aí eu sempre falo pra ele. Mas é aí e deu (M7, 47 anos, E).

O depoimento da participante M7 sugere que ela se mostra aberta para conversar com o filho sobre o risco do contágio por doenças sexualmente transmissíveis e a prevenção das mesmas e da gravidez, dando um suporte importante ao adolescente. Vários estudos verificaram que o diálogo sobre sexualidade entre pais e filhos tem forte influência sobre questões como gravidez na adolescência, iniciação sexual precoce e utilização ou não de métodos contraceptivos (Aquino et al., 2006; Bozon, \& Heilborn, 2006; Dias, \& Gomes, 2000; Pick, \& Palos, 1995). Pesquisa realizada por Pick e Palos (1995) no México constatou que as adolescentes que conversavam com frequência sobre sexo com suas mães tinham menor probabilidade de iniciar a vida sexual precocemente e de engravidar durante a adolescência e mais chances de utilizar algum método contraceptivo. De forma semelhante, um estudo desenvolvido por Bozon e Heilborn (2006), com jovens de Porto Alegre, Rio de Janeiro e Salvador, mostrou que as adolescentes que receberam das mães informações sobre contracepção apresentaram mais probabilidade de utilizar proteção em sua primeira relação sexual, quando comparadas às adolescentes que não tiveram isto de suas mães.

No entanto, cabe ressaltar que o diálogo sobre sexualidade não poderia resumir-se às questões preventivas. A fala anterior da participante M7 parece indicar que $o$ diálogo que ela estabelece com seu filho estaria focado exclusivamente em orientações sobre como evitar o contágio por doenças sexualmente transmissíveis e/ou a ocorrência de gravidez. A própria mãe afirma que "é isso aí e deu", ou seja, o diálogo sobre sexualidade parece não ir para além destas questões. Este discurso voltado apenas aos "cuidados" sugere que as mães parecem reduzir a questão da sexualidade ao ato sexual.

Segundo Oliveira (2012), em concordância com a teoria freudiana, já referida anteriormente, a sexualidade pode ser compreendida como um conjunto de ações que geram prazer, o qual não é necessariamente alcançado pela via genital, conforme muitas vezes é considerado pelo senso comum. Assim, "ao contrário do conceito de sexo, a sexualidade humana constitui parte integral da personalidade humana, integrando experiências afetivas exclusivamente pessoais, aprendizados socioculturais de convivência, crenças e valores construídos ao longo da história" (Ferrari, \& Vecina, 2002, p. 114).

Estudo de Dias e Gomes (2000) com adolescentes grávidas residentes em Porto Alegre - RS mostra que os pais das participantes não conseguiam transmitir às filhas adolescentes informações sobre sexualidade de forma adequada, o que ocorria geralmente de forma fragmentada, reduzindo-se a recomendações como "te cuida" e "avise quando chegar a hora". Jones (2010) chama atenção para os casos em que o diálogo sobre sexualidade entre pais e adolescentes fica centrado em recomendações acerca dos cuidados para se evitar gravidez e doenças sexualmente transmissíveis, enquanto as vivências afetivas e sexuais dos filhos recebem pouca atenção. No ponto de vista de Brandão (2004), as conversas sobre o tema no espaço familiar ocorrem ainda de forma pouco explícita. A autora aponta que são raras as famílias que conseguem tratar deste assunto com os filhos de forma direta, voltada para as suas experiências.

Destaca-se, neste caso, a importância de que todas as instituições que atendem adolescentes, tais como unidades básicas de saúde, escolas, projetos sociais, entre outras, incluam as famílias em suas ações para que estas se sintam apoiadas, protegidas e orientadas no sentido de proporcionar melhores condições para exercer a tarefa de educar os filhos sobre sexualidade (Almeida, \& Centa, 2009). Vários estudos apontam a necessidade de que as instituições escolares, as unidades de saúde e as famílias atuem de forma integrada no que se refere à educação sexual do adolescente (Gubert et al., 2009; Guimarães, Vieira, \& Palmeira, 2003). Este trabalho educativo integrado deveria acontecer no sentido de que os adolescentes tomassem conhecimento não apenas dos métodos contraceptivos, mas para pudessem refletir e discutir acerca das questões biopsicossociais relacionadas com a temática da sexualidade (Guimarães, Vieira, \& Palmeira, 2003).

$\mathrm{O}$ aconselhamento das filhas adolescentes com relação ao uso da pílula anticoncepcional também se fez presente no discurso de algumas mães, as quais relataram que procuravam salientar a ideia de que a pílula não previne DSTs e que essa prevenção só seria possível com o uso do preservativo. Isto pode ser visualizado nas falas que seguem:

Porque eu sempre né... digo "Olha, a camisinha não é pra evitá uma gravidez. A camisinha é pra evitá uma DST. Tem que cuidá nessa parte de doença, por isso 
tem que usá camisinha. Tem sempre que usá a camisinha. Tu tem que tomá o remédio também pra evitá a gravidez". Então eu sempre conversei com ela sobre isso. Sempre pegava no posto aqui ou comprava, sempre... logo que elas começaram a ter relação. Eu digo que elas têm que tê junto no bolso e dá pro cara colocá. E dizê: "Se tu não qué te cuidá, eu me protejo". Eu digo: "Seja bem direta". Porque não é feio uma mulher querê se protegê (M2, 32 anos, E).

Também chama atenção nas falas de algumas mães que possuem filhos adolescentes do sexo masculino a responsabilidade colocada sobre os mesmos com relação à prevenção da gravidez. Desse modo, a responsabilidade sobre esta questão parece ser cobrada pelas mães tanto dos rapazes quanto das meninas, mas a preocupação parece ser maior com o fato de um filho engravidar uma menina do que uma filha vir a engravidar.

Eu digo pra ela que isso aí tem que cuidá muito. Porque um filho a gente passa trabalho, mas a gente cria. Agora têm umas doença aí que se tu pegá vai pro resto da tua vida (M15, 30 anos, GF2).

Eu digo "Não, eu vô falá, porque as doenças tão aí, os riscos tão aí, tu tá te colocando em risco e às vez de outra pessoa, daqui a pouco tu tem um filho, né, daqui a pouco tu vai engravidá uma menina aí... E se tu engravidá uma menina, quem é que vai sofrê? A menina, em primeiro lugar, depois a criança e tu que vai tê que largá os teus objetivos pra criá teu filho". Então, acredito que os meus são esclarecidos, assim (M9, 33 anos, E).

O relato da mãe M9 salienta possíveis consequências negativas derivadas de uma situação de gravidez durante a adolescência. Pode-se pensar que não é à toa que uma das maiores preocupações das mães participantes resida na prevenção à gravidez, uma vez que muitas delas relataram ter engravidado durante a adolescência. A falta de informação e diálogo familiar sobre sexualidade foi apontada por elas como um dos principais fatores responsáveis pela ocorrência da gravidez em suas trajetórias. Diante da adolescência dos filhos, é possível que os pais vivenciem angústias pelo retorno de lembranças e fantasias em relação à sua própria adolescência e, em especial com relação à sexualidade.

\section{2. "Pras guria tu sabe porque tu é mulher, mas pra guri é bem mais difícil": diferenças entre meninos e meninas em relação ao diálogo sobre sexualidade}

Apesar de uma das mães entrevistadas ter relatado não identificar diferenças na abordagem do tema da sexualidade com meninos e meninas, "Eu falo com os dois [meninos e meninas] da mesma maneira" (M5, 34 anos, E), a maioria das participantes referiu ter mais dificuldade para conversar com os filhos adolescentes do que com as filhas.

Porque muitas vez temo eu e minha filha conversando, a gente tá numa boa conversando. Falando disso, daquilo... a gente conversa e tal. Daí os guri entram, acabô o assunto. A gente já fica... quieta, né. Eu acho que tem diferença sim. (...) Não é fácil pra mim conversá com os guri (M7, 47 anos, E).

Algumas mães relataram sentimentos de despreparo e vergonha para falar sobre certos assuntos relacionados à sexualidade com os filhos do sexo masculino. Esse aspecto evidenciou-se nas falas:

O meu de 15 anos fala, ele pergunta, mas eu, como eu sô mãe eu fico com vergonha. Eu fico com vergonha de respondê as coisas. Às vez ele fala declarado "Mãe, como é assim aquilo? Como é que é, mãe?". E eu já fico com vergonha de respondê. Mas eu tenho que respondê. Daí eu sento com ele, respondo (M12, 42 anos, GF1). Ele pegô o aparelho e chegô bem faceiro "Ó mãe, nasceu uns pelinho e eu tirei". "Mas meu filho, não pode tirá. E o teu pai não te explicô?". "Não, não me explicô nada". É umas coisa que tu fica mais... às vez tu fica perdida, né (M4, 45 anos, E).

Para algumas mães, os filhos por vezes também parecem sentir vergonha e evitar falar sobre assuntos relacionados à sexualidade com as mesmas. Elas relatam que eles teriam mais abertura com outros familiares do sexo masculino, como pai, padrasto e/ou irmão, o que pode ser visualizado nos depoimentos:

Acho que com guri é mais difícil, né. Com menino acho que é mais difícil a gente tê coragem de explicá, né. (...) Eles são mais acanhados, eu acho, né. Quando tu começa a explicá e eles já tão saindo de perto dizendo "Mãe, não precisa explicá coisa que eu já sei", e já vão saindo, né. Quando eu tentava falá eles não 
escutavam, daí me escutavam às vez de longe, lá do quarto, iam lá pra sala aí eu tentava conversá. E eles diziam: "Lá vem a mãe com essas historinha de novo. A senhora não tem vergonha de conversá isso com nós". Daí que eles me diziam... Eu acho que os guri são mais acanhado (M6, 47 anos, E). Às vezes tu vai faláe eles não querem... principalmente os meninos, "Mãe, tu é mulher e é minha mãe". Como é que eles vão falá comigo essas coisas? Entendeu? (...) Acho que ele tem vergonha de conversá isso comigo. Mas com o pai dele e o irmão dele não (M7, 47 anos, E).

Nesses trechos pode-se observar que, apesar das dificuldades relatadas para conversar sobre sexualidade com os meninos, as mães pareciam estar realizando tentativas para tanto. Porém, segundo as falas das mães, os filhos parecem fugir do assunto, dando a ideia de que já saberiam o suficiente, que teriam mais abertura com outros familiares (do sexo masculino) ou que sentiriam vergonha por falar sobre $\mathrm{o}$ assunto com as próprias mães.

Por outro lado, as participantes relataram maior facilidade e abertura para conversar sobre a temática com as filhas adolescentes. "Com as gurias eu era mais aberta, né, filha mulher, a gente é mais comunicativa. Até hoje, eu sô até hoje mais comunicativa com as minhas filhas, uma tem 27 e a outra tem 26"(M10, 47 anos, GF1). Neste sentido, destaca-se que, da mesma forma que as mães relataram uma maior facilidade para dialogar com as filhas sobre o tema, estudos realizados com adolescentes do sexo feminino mostraram a maior ocorrência do diálogo sobre o tema entre mães e filhas (Bozon, \& Heilborn, 2006; Ressel et al., 2011; Savegnago, 2011.).

Pesquisa realizada por Bozon e Heilborn (2006) enfatiza as diferenças de gênero na socialização referente à sexualidade. Evidenciou-se que, para as adolescentes participantes do estudo, a mãe era considerada uma das principais fontes de informações referentes à gravidez e à contracepção. Por outro lado, o papel do pai diante destas questões foi considerado praticamente nulo. Os adolescentes do sexo masculino, por sua vez, referiram o pai como uma das fontes de informação sobre sexualidade. Esta questão também se fez presente no discurso de algumas mães participantes do presente estudo, como se pode observar no relato que segue:

Eu acho um pouco difícil. Pra os guri é difícil. Pras guria tu sabe porque tue mulher, mas pra guri é bem mais difícil. Porque pra homem tu não sabe muita coisa. Pra guria é mais... Pra guri não tem muita conversa com a mãe, é mais com o pai, né. Menina não. Menina chega mais perto da mãe e ela conversa, explica. Mas menino não... Aí que tu fica perdida né (M4, 45 anos, E).

A fala de M4 coincide com um estudo realizado com adolescentes de grupos populares de Santa Maria - RS, no qual as adolescentes relataram ser mais fácil conversar com a mãe do que com o pai, pois a mãe já teria passado pelas experiências que elas estavam passando, como a ocorrência da menstruação, e por isso saberia mais sobre assuntos relacionados ao sexo feminino. Por outro lado, o pai foi referenciado como alguém que estaria mais apto para falar com os meninos, uma vez que ele teria conhecimento das "regras de guri", pois "ele já foi guri um dia" (Savegnago, \& Arpini, 2014).

No entanto, considerando-se os relatos das mães de que elas teriam mais facilidade e abertura para conversar sobre sexualidade com as filhas adolescentes e os pais com os filhos, como ficaria a situação dos meninos pertencentes a contextos de famílias monoparentais femininas ou onde o pai encontra-se pouco presente? Analisando-se os arranjos familiares no Brasil, destaca-se que, nas últimas décadas, houve um aumento considerável no número de famílias monoparentais, a maioria delas constituída pela presença da mãe com seus filhos (Berquó, 1998; Ferreira, 2001; Peres, 2001; Rizzini, 2001). Esta realidade evidenciou-se nos grupos focais e entrevistas do presente estudo, uma vez que, das 17 mães participantes, cinco constituíam famílias monoparentais. Segundo dados do IBGE, a proporção de mulheres sem cônjuges e com filhos subiu de 15,06\%, em 1992, para 17,4\%, em 2009. Observou-se ainda um crescimento significativo no índice de mulheres consideradas as pessoas de referências das famílias ou domicílios, passando de 16,99\%, em 1981, para 35,17\%, em 2009 (Berquó, 1998; Ferreira, 2001).

Dessa forma, nas famílias de grupos populares, as mulheres, em especial a mãe, vêm assumindo um papel fundamental na educação e cuidado dos filhos e na organização e sustento da casa (Amazonas, Damasceno, Terto, \& Silva, 2003; Peres, 2001; Rizzini, 2001). Sarti (2005) aponta a mãe como a principal figura de referência nas famílias pertencentes a estes grupos, sendo vista muitas vezes como aquela que cuida, protege e se preocupa. Desse modo, pode-se pensar que nestes casos a tarefa de dialogar sobre sexualidade com os filhos recai exclusivamente sobre a mãe. 
A partir do estudo desenvolvido por Savegnago e Arpini (2014), identificou-se que as meninas adolescentes apontavam que o pai geralmente não se mostrava aberto a elas para o diálogo sobre sexualidade. De forma semelhante, pesquisa realizada por Jones (2010) em Trelew, cidade da Patagônia, Argentina, mostrou que dois terços das adolescentes entrevistadas nunca falaram sobre sexualidade com o pai. Por outro lado, é possível que por vezes a mãe não se sinta preparada para dialogar com os filhos sobre este assunto, delegando ao pai esta tarefa, como fica evidente na fala que segue. "E tem muitas coisas que eu digo pra ele 'Conversa com o teu pai'. Quando tem alguma coisa que ele vêm perguntá assim eu digo 'Fala pro teu pai' 'Isso aí é com você, tué homem, né. Por isso que o eu mando o J [filho] falá contigo'. Porque eu sô meia assim..." (M10, 47 anos, GF1).

A participante M1 aborda a questão do diálogo sobre sexualidade com as filhas de forma diferente do que foi apontado pela maioria das mães participantes. Na perspectiva desta mãe, o pai teria melhores condições de abordar o tema com a filha adolescente.

\begin{abstract}
Não. Não, não, ele [marido] não falava nada, não comentava. Até eu falei que pra nossa filha tinha que comentá, falá bastante com ela, explicá bastante com ela. Como ele era pai, ele sabia o lado dele de homem, né. Que homem é diferente de mulher. Então ele tinha que explicá pra filha dele como é que era o jeito do homem, quando ela estivesse maior, mais grande, né, mais de idade. Que ele tinha que conversá com ela bastante sobre isso, como pai, né, explicá, falá com ela, né. Não tinha de não falá, porque a gente tem que explica pra ela: "Ó, minha filha, é assim, assim, assim, né. O pai é homem, o pai sabe, o pai entende certas coisas". Eu disse pra ele que não precisava tê medo, tê vergonha, essas coisa assim, de falá com ela (M1, 38 anos, E).
\end{abstract}

Este aspecto é concordante com a pesquisa de Castro, Abramovay e Silva (2004), que ouviu centenas de pais, professores e alunos em quatorze capitais brasileiras, na qual houve referência a situações em que havia uma melhor vinculação entre pai e filha no que se refere ao diálogo sobre sexualidade, em casos nos quais a mãe não apresentava abertura ou iniciativa para este tipo de conversa. Este aspecto também se fez presente na fala de M7 (47 anos, E): "Porque... como tu vê... (risos). Eu sô... Eu se não fosse o F. [companheiro], muita coisa eu também não saberia conversá nada. É mais ele, né".
Nesse sentido, destaca-se a existência de vários estudos que mostram pais mais participativos e presentes na vida familiar (Bustamante, 2005; Gomes, \& Resende, 2004; Silva, \& Piccinini, 2007; Souza, \& Benetti, 2008). Nas últimas décadas, surgiu o conceito do "novo pai", o qual percebe a paternidade como uma oportunidade de expressar sentimentos, participando de maneira ativa no cuidado dos filhos e tendo uma relação igualitária com a parceira (Bustamante, 2005).

\section{3. "Que adolescente acha que sabe tudo, né. (...) Mas acredito que eles buscam clareza": afinal, o que os adolescentes esperam dos pais?}

Estudos vêm destacando que a sociedade atual encontra-se marcada pela presença intensa da temática sexo/sexualidade em diversos contextos. Assim, o adolescente está constantemente em contato com estímulos relacionados à sexualidade e pode acessar com facilidade uma ampla variedade de informações sobre o assunto (Cano, \& Ferriani, 2000; Predebon, 2002). Esta realidade muitas vezes pode confundir os pais com relação ao saber dos filhos sobre a temática, levando-os a acreditar que $o$ adolescente saberia o suficiente.

No entanto, evidencia-se que, apesar do amplo acesso a informações sobre sexualidade, não significa que as dúvidas dos adolescentes com relação ao tema tenham sido resolvidas. Desse modo, os pais não poderiam ser liberados de sua importante tarefa no tratamento do tema (Savegnago, \& Arpini, 2014). A curiosidade e o desejo de falar sobre esse tema evidenciouse em estudo anterior realizado com meninas sobre a questão do diálogo sobre sexualidade no âmbito familiar. Destacou-se que, mesmo diante da complexidade desse tema e da ausência de diálogo dos pais sobre sexualidade, o desejo de saber e falar sobre se fazia presente (Savegnago, \& Arpini, 2013).

Nesse sentido, as mães participantes das entrevistas foram convidadas a falar sobre o que acreditavam que os adolescentes esperavam dos pais em relação às questões que envolvem a sexualidade. Algumas delas referiram que por vezes os filhos parecem acreditar que sabem mais que os próprios pais em relação ao assunto.

Olha, o que os adolescentes de hoje esperam... não esperam nada. Os adolescentes não esperam nada. Os adolescentes de hoje eles pensam, eles agem e eles acham que sabem mais que os pais. E muitas vezes sa- 
bem. Que os pais nem conversam com eles sobre nada (M2, 32 anos, E).

A participante M9, por sua vez, apresentou tanto a percepção de que os adolescentes já teriam informações suficientes sobre o assunto quanto a ideia de que, apesar disso, eles esperariam esclarecimentos e abertura para o diálogo por parte dos pais.

Isso é muito relativo, né, isso vai muito assim... em relação o que eles esperam... que os pais sejam companheiros, que quando eles vêm perguntá alguma coisa, que os pais deem uma resposta clara. Eu, pra mim é isso. Já outros não querem falá, né. Que nem os meus, às vezes eu vô falá alguma coisa e eles falam assim "Ai mãe, já vai começá?". Isso é uma frase que se ouve muito dos adolescentes: "Já vai começa. Por que tu qué se metê na minha vida? Não sei por que fica falando essas coisas comigo, que eu sei...." Que adolescente acha que sabe tudo né, eles acham que os pais não sabem nada. Eles não olham pelo lado que tu já viveu, que tu já teve experiência, que se tu vai abordá alguma coisa é porque tu já teve experiência naquilo ali. Mas acredito que eles buscam clareza, né, nas respostas daquilo ali que eles vêm buscá (M9, 33 anos, E).

Em relação a este aspecto, Dias e Gomes (1999) sinalizam para situações em que os pais supõem que os filhos estejam bem informados em relação às questões que envolvem a sexualidade. No entanto, pode ocorrer que as percepções que os pais possuem em relação ao adolescente no que se refere à sexualidade não correspondam à realidade vivenciada pelo mesmo e ao que ele realmente demanda dos pais. Um exemplo dessa disparidade entre a percepção dos pais e do adolescente encontra-se em um estudo de Pick e Palos (1995), realizado no México. Os autores apontam casos em que adolescentes relataram mais dificuldade na comunicação sobre sexo/sexualidade com seus pais do que estes pais afirmavam perceber. Dessa forma, cabe ressaltar que, por mais que os adolescentes tenham informações sobre sexualidade, ou se mostrem pouco receptivos às orientações familiares, isso não prescinde os pais de assumir sua tarefa. Neste sentido evidenciam-se falas de mães que acreditam que o adolescente espere abertura dos pais para o diálogo sobre o tema.

Esperam que a gente vá explicá o que a gente sabe pra eles, né, uma coisa boa, não uma coisa ruim, né. Os pais nunca vão... como diz o ditado, botá o filho pro mato, levá o filho pras coisa errada, né, nunca, jamais, né. Sempre vai tentá o bom, o melhor pros filho (M1, 38 anos, E).

De mim eu acho que eles esperam companheirismo assim... podê contá comigo... seria isso. Eu acho, né... podê falá também... eu acho que é isso... (M5, 34 anos, E).

Como retratam alguns estudos, é difícil saber exatamente o que esperam os adolescentes de seus pais. Contudo, supor que os filhos esperam algo de seus pais em relação a esse tema parece ser uma tarefa que se mantém mesmo quando o volume de informações e estímulos parece ser por vezes excessivo.

\section{Considerações finais}

A partir do exposto, destaca-se a importância de se atentar para a necessidade de que os diálogos sobre sexualidade entre pais e filhos não fiquem limitados às questões relativas à prevenção de doenças e gravidez. Além disso, o diálogo sobre sexualidade deveria ir além da simples transmissão de informações, pois demanda que os pais ultrapassem várias barreiras para alcançarem proximidade e sintonia com o momento existencial e as experiências pelos quais o filho adolescente está passando. Considerando o exposto em relação ao tema da sexualidade e a perspectiva a partir da qual o tema foi abordado, é inegável que tanto o pai quanto a mãe têm importante papel no desenvolvimento da sexualidade de seus filhos, sendo o diálogo sobre o tema uma tarefa que deveria ser assumida por ambos.

Apesar da visibilidade dos aspectos informativos a respeito da sexualidade, os pais não estariam desresponsabilizados de assumir seu papel fundamental no tratamento deste tema com seus filhos. Estes podem ter acesso a informações através de outros meios, como escola, internet, televisão e amigos, mas isso não substitui o diálogo familiar, o qual pode fornecer ao adolescente os valores e crenças próprios da família, além de ser, na maioria das vezes, o espaço mais seguro onde ele pode expor suas dúvidas, angústias e ideias sobre a temática.

Quanto às possíveis contribuições da Psicologia em relação a esta questão, sugere-se que, em espaços de atenção à saúde pública e assistência social onde haja inserção do psicólogo, como Centros de Referência em Assistência Social, Unidades Básicas de Saúde, ou NASF (Núcleo de Apoio Sociofamiliar), escolas e projetos sociais, sejam oportunizadas ações voltadas para a temática da sexualidade. Estas ações poderiam ser desenvolvidas por 
meio de oficinas e grupos de discussão voltados para pais e mães de adolescentes, oferecendo a eles estratégias para melhor lidar com as demandas dos adolescentes referentes a essa temática. Destaca-se ainda a importância da construção de espaços grupais de conversa com adolescentes que envolvam o tema da sexualidade. O apoio do psicólogo às escolas, neste sentido, também é fundamental, uma vez que a sexualidade se constitui em um dos temas transversais em educação.

Além do profissional da Psicologia, destaca-se a importância de que os demais profissionais da saúde

\section{Referências}

Almeida, A. C. C. H., \& Centa, M. L. (2009). A família e a educação sexual dos filhos: implicações para a Enfermagem. Acta Paulista de Enfermagem, 22(1), 71-76. doi:10.1590/S0103-21002009000100012

Amazonas, M. C. L. A., Damasceno, P. R., Terto, L. M. S., \& Silva, R. R. (2003). Arranjos familiares de crianças das camadas populares. Psicologia em Estudo, 8(num. esp.), 11-20. doi:10.1590/S141373722003000300003

Aquino, E. M. L., Almeida, M. C., Araújo, M. J., \& Menezes, G. (2006). Gravidez na adolescência: a heterogeneidade revelada. In M. L. Heilborn, E. M. L. Aquino, M. Bozon, \& D. R. Knauth (Eds.), Oaprendizado da sexualidade: reprodução e trajetórias sociais de jovens brasileiros (pp. 309-360). Rio de Janeiro, RJ: Garamond.

Barbosa, S. M., Costa, P. N. P., \& Vieira, N. F. C. (2008). Estágios de mudança dos pais nas conversas com os filhos sobre prevenção HIV/AIDS. Revista Latino-americana de Enfermagem, 16(6), 1-7. doi:10.1590/S0104-11692008000600013

Bardin, L. (1977). Análise de conteúdo. Lisboa: Editora 70. Berquó, E. (1998). Arranjos familiares no Brasil: uma visão demográfica. In L. M. Schwarcz (Ed.), História da vida privada no Brasil: contrastes da intimidade contemporânea. São Paulo, SP: Companhia das Letras.

Borges, A. L. V., Latorre, M. R. D. O., \& Schor, N. (2007). Fatores associados ao início da vida sexual de adolescentes matriculados em uma unidade de saúde da família da zona leste do município de São Paulo, Brasil. Cadernos de Saúde Pública, 23(7), 1583-1594. doi:10.1590/S0102-311X2007000700009

Borges, A. L. V., Nichiata, L. Y. I., \& Schor, N. (2006). Conversando sobre sexo: a rede sociofami- e os professores atuem no sentido de oferecer espaços de escuta e atenção aos adolescentes e seus familiares em relação às questões que dizem respeito à sexualidade. Para tanto, faz-se necessário que estes profissionais sejam capacitados para que suas intervenções possam ir além do modelo biológico, e iniciar discussões e reflexões acerca da sexualidade que contemplem as perspectivas físicas, psicológicas, emocionais, culturais e sociais, no intuito de estarem mais próximos do adolescente e alcançar com maior êxito a promoção de sua saúde integral.

liar como base de promoção da saúde sexual e reprodutiva de adolescentes. Revista Latino-americana de Enfermagem, 14(3), 422-427. doi:10.1590/S0104-11692006000300017

Bozon, M., \& Heilborn, M. L. (2006). Iniciação à sexualidade: modos de socialização, interações de gênero e trajetórias individuais. In M. L. Heilborn, E. M. L. Aquino, M. Bozon, \& D. R. Knauth (Eds.), O aprendizado da sexualidade: reprodução e trajetórias sociais de jovens brasileiros (pp. 155-206). Rio de Janeiro, RJ: Garamond.

Brandão, E. R. (2004). Iniciação sexual e afetiva: exercício da autonomia juvenil. In M. L. Heilborn (Ed.), Família e sexualidade (pp. 63-86). Rio de Janeiro, RJ: Editora FGV.

Brasil. (2005). Política Nacional de Assistência Social - PNAS. Brasília, DF: Ministério do Desenvolvimento Social e Combate à Fome.

Bustamante, V. (2005). Ser pai no subúrbio ferroviário de salvador: um estudo de caso com homens de camadas populares. Psicologia em Estudo, 10(3), 393-402. doi: 10.1590/S1413-73722005000300007

Cano, M. A. T., \& Ferriani, M. G. C. (2000). A família frente à sexualidade dos adolescentes. Acta Paulista de Enfermagem, 13(1), 38-46.

Castro, M. G., Abramovay, M., \& Silva, L. B. (2004). Juventudes e sexualidade. Brasília, DF: UNESCO Brasil.

Desprats-Péquignot, C. (1992/1994). A psicopatologia da vida sexual. Campinas: Papirus.

Dias, A. C. G., \& Gomes, W. B. (1999). Conversas sobre sexualidade na família e gravidez na adolescência: a percepção dos pais. Estudos de Psicologia, 4(1), 79-106. doi:10.1590/S1413-294X1999000100006

Dias, A. C. G., \& Gomes, W. B. (2000). Conversas, em família, sobre sexualidade e gravidez na adolescência: percepção das jovens gestantes. 
Psicologia: Reflexão e Crítica, 13(1), 109-125. doi:10.1590/S0102-79722000000100013

Ferrari, D. C. A., \& Vecina, T. C. C. (2002). O fim do silêncio na violência familiar: teoria e prática. São Paulo, SP: Ágora.

Ferreira, F. P. M. (2001). A família brasileira hoje: estrutura, dinâmica, distribuição de papeis, demanda por serviços. In M. Stengel et al. (Eds.), Políticas públicas de apoio sociofamiliar (pp. 71-84, Coleção Infância e Adolescência). Belo Horizonte, MG: PUC Minas.

Freud, S. (1996). Esboço de psicanálise. In J. Salomão (Ed.), Edição standard brasileira de obras completas de Sigmund Freud (Vol. 23, pp. 151-221). Rio de Janeiro, RJ: Imago. (Original publicado em 1940)

Freud, S. (1996). Os instintos e suas vicissitudes. In J. Salomão (Ed.), Edição standard brasileira das obras psicológicas completas de Sigmund Freud (Vol. 14, pp. 115-144). Rio de Janeiro, RJ: Imago. (Original publicado em 1915)

Freud, S. (1996). Três ensaios sobre a teoria da sexualidade. In J. Salomão (Ed.), Edição standard brasileira de obras completas de Sigmund Freud (Vol. 7, pp. 117-231). Rio de Janeiro, RJ: Imago. (Original publicado em 1905)

Gaskell, G. (2005). Entrevistas individuais e grupais. In M.W. Bauer, \& G. Gaskell (Eds.), Pesquisa qualitativa com texto, imagem e som: um manual prático (pp. 64-89). Petrópolis, RJ: Vozes.

Gomes, A. J. S., \& Resende, V. R. (2004). O pai presente: o desvelar da paternidade em uma família contemporânea. Psicologia: Teoria e Pesquisa, 20(2), 119-125. doi:10.1590/S0102-37722004000200004

Gubert, F. A., Vieira, N. F. C., Pinheiro, P. N. C., Oliveira, E. N., \& Costa, A. G. M. (2009). Cuidado de enfermagem na promoção do diálogo mãe e filha adolescente: estudo descritivo. Brazilian Journal of Nursing, 8(3). Recuperado de http://www. objnursing.uff.br/index.php/nursing/article/ view/j.1676-4285.2009.2648/578

Guimarães, A. M. D. N., Vieira, M. J., \& Palmeira, J. A. (2003). Informações dos adolescentes sobre métodos anticoncepcionais. Revista Latino Americana de Enfermagem, 11(3), 293-298. doi:10.1590/S0104-11692003000300005

Heilborn, M. L. (2012). Por uma agenda positiva dos direitos sexuais da adolescência. Psicologia Clínica, 24(1), 57-68. doi:10.1590/S0103-56652012000100005
Instituto Brasileiro de Geografia e Estatística (2012). Pesquisa Nacional por Amostra de Domicílios 2001-2009. Recuperado de http://seriesestatisticas.ibge.gov.br/

Instituto Brasileiro de Geografia e Estatística (2012). Pesquisa Nacional por Amostra de Domicílios 1981-1990. Recuperado de http://seriesestatisticas.ibge.gov.br/

Jones, D. E. (2010). Diálogos entre padres y adolescentes sobre sexualidad: discursos morales y médicos en la reproducción de las desigualdades de género. Interface - Comunicação, Saúde, Educação, 14(32), 171-82. doi:10.1590/S1414-32832010000100014

Kehl, M. R. (2004). A juventude como sintoma da cultura. In R. Novaes, \& P. Vannuchi (Eds.), Juventude e sociedade: trabalho, educação, cultura e participação (pp. 89-114). São Paulo, SP: Fundação Perseu Abramo.

Laplanche, J., \& Pontalis, J. B. (1996). Vocabulário da psicanálise. São Paulo, SP: Martins Fontes.

Levisky, D. L. (1995). Adolescência: reflexões psicanalíticas. Porto Alegre, RS: Artes Médicas.

Macedo, S. R. H., Miranda, F. A. N., Pessoa Junior, J. M., \& Nobrega, V. K. M. (2013). Adolescência e sexualidade: scripts sexuais a partir das representações sociais. Revista Brasileira de Enfermagem, 66(1), 103-109. Doi:10.1590/S0034-71672013000100016

Marty, F., \& Cardoso, M. R. (2008). Adolescência: um percurso franco-brasileiro. In M. R. Cardoso, \& F. Marty (Eds.), Destinos da adolescência (pp. 9-16). Rio de Janeiro, RJ: 7 Letras.

Mayorga,C. (2006).Identidadeseadolescências:umadesconstrução. Pesquisas e Práticas Psicossociais, 1(1), 1-20. Recuperado de http://www.ufsj.edu.br/portal -repositorio/File/revistalapip/Identidades_e_Adolescencias_-_C_Mayorga.pdf

Oliveira, D. L. (2012). Sexo e saúde na escola: isso não é coisa de médico? In D. E. E. Meyer et al. (Eds.), Saúde, sexualidade e gênero na educação de jovens (pp. 103-112). Porto Alegre, RS: Mediação.

Peres, V. L. A. (2001). Concepções de família em população de periferia urbana. In S. M. G. Sousa (Ed.), Infância, adolescência e família (pp. 217-230). Goiânia, GO: Cânone Editorial.

Pick, S., \& Palos, P. A. (1995). Impact of the family on the sex lives of adolescents. Adolescence, 30(119), 667-675.

Pratta, E. M. M., \& Santos, M. A. (2007). Família e adolescência: a influência do contexto fami- 
liar no desenvolvimento psicológico de seus membros. Psicologia em Estudo, 12(2), 247-256. doi:10.1590/S1413-73722007000200005

Predebon, J. C. (2002). Conversando sobre sexo na família com filhos adolescentes. In A. Wagner (Ed.). Família em cena: tramas, dramas e transformações (pp. 159-171). Petrópolis, RJ: Vozes.

Ressel, L. B., Junges, C. F., Sehnem, G. D., Sanfelice, C. (2011). A influência da família na vivência da sexualidade. Escola Anna Nery (impr.), 15(2), p. 245250. doi:10.1590/S1414-81452011000200005

Rizzini, I. (2001). Crianças, adolescentes e suas bases familiares: tendências e preocupações globais. In S. M. G. Sousa, \& I. Rizzini (Eds.), Desenhos de família: criando os filhos: a família goianiense e os elos parentais (pp. 23-44). Goiânia, GO: Cânone Editorial.

Sarti, C. A. (2005). A família como espelho: um estudo sobre a moral dos pobres. São Paulo, SP: Cortez.

Savegnago, S. D. O. (2011). Conversando sobre sexualidade na família: o olhar de meninas de grupos populares [Trabalho de conclusão de curso]. Curso de Psicologia, Universidade Federal de Santa Maria. Santa Maria, RS.

Savegnago, S. D. O., \& Arpini, D. M. (2013). Conversando sobre sexualidade na família: olhares de meninas de grupos populares. Cadernos de Pesquisa, 43(150), 924-947. doi:10.1590/S0100-15742013000300010

Savegnago, S. D. O., \& Arpini, D. M. (2014). Diálogos sobre sexualidade na família: reflexões a partir do discurso de meninas. Psicologia Argumento, 32(76), 57-67. Recuperado de http://www2.pucpr. $\mathrm{br} / \mathrm{reol} /$ index.php/PA?ddl=14562\&dd99=view

Savietto, B. B., \& Cardoso, M. R. (2006). Adolescência: ato e atualidade. Revista mal-estar e subjetividade, 6(1), 15-43. Recuperado de http://pepsic.bvsalud.org/pdf/malestar/v6n1/03.pdf

Silva, M., \& Piccinini, C. A. (2007). Sentimentos sobre a paternidade e o envolvimento paterno: um estudo qualitativo. Estudos de Psicologia, 24(4), 561-573. doi:10.1590/S0103-166X2007000400015

Siqueira, A. C., Arpini, D. M., \& Savegnago, S. D. O. (2011). Família e abuso sexual na perspectiva de adolescentes em situação de vulnerabilidade social. Aletheia, 34, 109-122. Recuperado de http:// www.redalyc.org/articulo.oa?id=115022577009
Sousa, L. B., Fernandes, J. F. P., \& Barroso, M. G. T. (2006). Sexualidade na adolescência: análise da influência de fatores culturais presentes no contexto familiar. Acta Paulista de Enfermagem, 19(4), 408-13. doi:10.1590/S0103-21002006000400007

Souza, C. L. C., \& Benetti, S. P. C. (2008). Paternidade e desemprego: características do envolvimento paterno e aspectos do relacionamento familiar. Contextos Clínicos, 1(2), 61-71. doi:10.4013/ctc.20082.02

Sprinthall, N. A., \& Collins, W. A. (2003). Psicologia do adolescente: uma abordagem desenvolvimentista (C. M. C. Vieira, Trans.). Lisboa: Fundação Calouste Gulbenkian.

Takiuti, A. D. (1997). A saúde da mulher adolescente- 1993. In F. R. Madeira (Ed.), Quem mandou nascer mulher? estudos sobre crianças e adolescentes pobres no Brasil (pp. 213-290). Rio de Janeiro, RJ: Rosa dos Tempos.

\section{Sabrina Dal Ongaro Savegnago}

Doutoranda em Psicologia pela Universidade Federal do Rio de Janeiro, Rio de Janeiro - RJ. Brasil.

E-mail: binasavegnago@yahoo.com.br

\section{Dorian Mônica Arpini}

Docente da Universidade Federal de Santa Maria, Santa Maria - RS. Brasil.

E-mail: monica.arpini@gmail.com

\section{Endereço para envio de correspondência:}

Universidade Federal de Santa Maria, Centro de

Ciências Sociais e Humanas, Departamento de Psicologia, Floriano Peixoto. Centro. CEP: 97010-000. Santa Maria - RS. Brasil.

Recebido 06/08/2014

Aprovado 20/01/2016

Received 08/06/2014

Approved 01/20/2016

Recibido 06/08/2014

Aceptado 20/01/2016 
Como citar: Savegnago, S. D. O., \& Arpini, D. M. (2016). A abordagem do tema sexualidade no contexto familiar: o ponto de vista de mães de adolescentes. Psicologia: Ciência e Profissão, 36(1): 130-144. doi:10.1590/1982-3703001252014

How to cite: Savegnago, S. D. O., \& Arpini, D. M. (2016). Approach to the theme of sexuality in the family context: the point of view of adolescents' mothers. Psicologia: Ciência e Profissão, 36(1): 130-144. doi:10.1590/1982-3703001252014

Cómo citar: Savegnago, S. D. O., \& Arpini, D. M. (2016). El abordaje del tema de la sexualidad en el contexto familiar: el punto de vista de madres de adolescentes. Psicologia: Ciência e Profissão, 36(1): 130-144. doi:10.1590/1982-3703001252014 